\title{
Psychotherapy Utilization and Presenting Concerns Among Polynesian American College Students
}

\author{
Kawika Allen \\ Brigham Young University, gekawika_allen@byu.edu \\ Jon Cox \\ Brigham Young University \\ Timothy B. Smith \\ Brigham Young University \\ Ofa Hafoka \\ Brigham Young University \\ Derek Griner

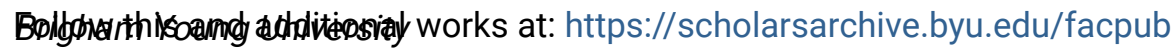 \\ Part of the Mental and Social Health Commons
}

See next page for additional authors

Original Publication Citation

Allen, G. E. K., Cox, J., Smith, T. B., Griner, D., Beecher, M., *Hafoka, O. (2016). Psychotherapy utilization and presenting concerns among Polynesian American college students. The Counseling Psychologist, 44 (1), 28-49.

\section{BYU ScholarsArchive Citation}

Allen, Kawika; Cox, Jon; Smith, Timothy B.; Hafoka, Ofa; Griner, Derek; and Beecher, Mark, "Psychotherapy Utilization and Presenting Concerns Among Polynesian American College Students" (2016). Faculty Publications. 3180.

https://scholarsarchive.byu.edu/facpub/3180

This Peer-Reviewed Article is brought to you for free and open access by BYU ScholarsArchive. It has been accepted for inclusion in Faculty Publications by an authorized administrator of BYU ScholarsArchive. For more information, please contact ellen_amatangelo@byu.edu. 


\section{Authors}

Kawika Allen, Jon Cox, Timothy B. Smith, Ofa Hafoka, Derek Griner, and Mark Beecher

This peer-reviewed article is available at BYU ScholarsArchive: https://scholarsarchive.byu.edu/facpub/3180 


\section{Psychotherapy \\ Utilization and}

Presenting Concerns

Among Polynesian
The Counseling Psychologist 2016, Vol. 44(I) 28-49

(C) The Author(s) 2015

Reprints and permissions: sagepub.com/journalsPermissions.nav DOI: 10.1177/0011000015617534 tcp.sagepub.com

@SAGE American College Students

\author{
G. E. Kawika Allen', Jon Cox', \\ Timothy B. Smith', Ofa Hafoka', \\ Derek Griner', and Mark Beecher'
}

\begin{abstract}
In this study, we examined psychotherapy utilization, presenting concerns, reported distress levels, and psychotherapy outcomes among Polynesian American students presenting for services at a counseling center. We collected data at intake, during therapy sessions, and at termination for 415 Polynesian American and 18,117 European American students over a 17-year period. Polynesian American students were equally likely to utilize counseling services as European American students but were more likely to drop out earlier. At intake, these students reported higher numbers of presenting concerns and greater levels of emotional and psychological distress than European American students. Polynesian American students reported significantly higher scores on racial discrimination, physical abuse, and family dependence. Implications for counseling center programs and services are discussed.
\end{abstract}

\title{
Keywords
}

Polynesian American college students, university counseling centers, college student psychological adjustment, counseling utilization

'Brigham Young University, Provo, UT, USA

\section{Corresponding Author:}

G. E. Kawika Allen, Brigham Young University, 273 MCKB, Provo, UT 84602, USA.

Email: gekawika_allen@byu.edu 
Many college students across the United States seek out and attend personal counseling for psychological and emotional assistance (Kitzrow, 2003). These services are typically offered on campuses at university or college counseling centers. Due to the current demands in a changing and evolving college environment, heightened psychological concerns among students (Kitzrow, 2003) have made campus personal counseling essential. These student needs can include effective brief therapy, group counseling, culturally adapted counseling (Griner \& Smith, 2006), outreach and consultation, and other important student mental health services across campus at all institutional levels (Archer \& Cooper, 1998; Kitzrow, 2003).

Findings regarding college counseling utilization rates among racial and ethnic minority students have been mixed. Although Kearney, Draper, and Barón (2005) reported lower utilization among minority students than among European American college students, other researchers (Hayes et al., 2011) found that, in 66 colleges and universities in the United States, counseling utilization for ethnic minorities was consistent with the rate of enrollment for students of each ethnicity examined. Nonetheless, underutilization of services among racial and ethnic minority students on campuses has been a long-standing issue and continues to be a concern for university and college counseling centers (Ibaraki \& Hall, 2014). Particularly disquieting is that Asian American students, followed by Latino and African American students, although more hesitant to seek help, have been diagnosed with higher distress levels at intake than European American students (Kearney et al., 2005).

\section{A Neglected Population}

One of the underserved populations of racial and ethnic minority students that warrant specific attention by mental health centers in universities and colleges across the United States is Polynesian Americans. Virtually no research has documented the psychological and health concerns or the treatment of these college students. In addition to being underrepresented in clinical services, Polynesian American students have been underrepresented in the literature on counseling and multicultural psychology. Over the years, Latinos/as, Asian Americans, African Americans, and Native Americans have been the main racial/ethnic minority subjects for researching and developing psychological issues (Allen \& Heppner, 2011). The Polynesian American population, including Polynesian American students, has been one of the fastest growing racial and ethnic group in the United States (U.S. Bureau of the Census, 2010). Yet, little has been published on the population's psychological well-being. Some research has focused on the psychological well-being of Native Hawaiian adolescents (e.g., Carlton et al., 2006); 
however, little is known about the psychological needs of the broader Polynesian American college student population. Thus, the mental health issues and treatment of Polynesian American college students, particularly those who reside in the United States, need more focused research attention.

\section{Need for Distinct Identity}

Aside from limited psychological research pertaining to Polynesian Americans, this group is also distinct from other racial and ethnic populations. People living in the Polynesian islands share similar cultural and family customs, values, and traditions, and their languages have similarities as well (e.g., South Pacific, Polynesian Triangle; Allen, Garriott, Reyes, \& Hsieh, 2013; Allen \& Heppner, 2011; Allen \& Smith, 2015). Despite having similar values and traditions, Polynesians choose to identify specifically with their island of origin, cultural heritage, and racial lineage in a very proud, honorable, and respectful manner, while also respecting Polynesians from other islands within the triangle. Although research has been conducted on Native Hawaiians, which are part of the Polynesian community (McCubbin, 2006; McCubbin \& Dang, 2010; McCubbin, Ishikawa, \& McCubbin, 2008), there is still a dearth of empirical studies involving other Polynesians (e.g., Samoans, Tongans, Fijians, Tahitians, Maoris) and their psychological adjustment and well-being in the mainland United States, particularly around counseling utilization rates, counseling best practices, and culture-specific counseling interventions in their cultural contexts.

Because there is limited research focused on adjustment and distress among Polynesians, little is known about the specific psychological concerns, issues, and emotional difficulties among Polynesian American college students. Although more research is needed specifically for this age group, some recent research has found that collectivistic coping strategies such as family support, religious and spiritual practices, and open family communication are effective methods to buffer against some emotional difficulties in older Polynesian Americans (Allen \& Heppner, 2011; Allen \& Smith, 2015). In addition, a strong racial and ethnic identity among Polynesian Americans can lead to positive mental health (Allen et al., 2013). It is possible that the positive buffering effects against psychological struggles among older Polynesian Americans could also remedy some of the concerns among Polynesian American college students across the United States.

Despite this lack of research, many clinicians and researchers believe that counseling center utilization, clients' presenting problems, ethnic identity, religiosity, coping styles, and therapy effectiveness for various ethnic minority college students, and particularly Polynesian American college students, 
may be different from those of typical European American college students (Allen \& Heppner, 2011; Allen et al., 2013; Allen \& Smith, 2015). Although some research has found that therapy effectiveness is the same across racial and ethnic groups, virtually no study has specifically examined Polynesian American college students separate from Asian American students, as the two groups have typically been lumped together in psychological research (Lambert et al., 2006). For clinicians in counseling centers, knowing more detailed information about the presenting concerns, utilization rates, and therapy outcomes of this neglected population can facilitate more culturally specific and appropriate interventions in therapy (Allen \& Heppner, 2011; Allen \& Smith, 2015).

\section{Research Questions}

Although some studies have centered on coping and racial identity among Polynesian individuals in the United States (Allen et al., 2013), current literature focused on counseling utilization, presenting concerns, distress levels, and counseling service effectiveness for U.S. Polynesian American college students has been sparse. To help fill this gap in the literature, our study addressed the following research questions:

Research Question 1: What are the utilization and dropout rates of Polynesian American students in psychotherapy in a university counseling center?

Research Question 2: What are the common presenting concerns that bring Polynesian American students to counseling centers? What are the differences between concerns of European American and Polynesian American students?

Research Question 3: How do European American and Polynesian American students compare related to improvements in treatment-asusual (individual counseling, group therapy, and biofeedback services)?

Research Question 4: Do Polynesian American student-client reports regarding racial discrimination, physical abuse, and family issues differ from those of European American students?

\section{Method}

\section{Participants}

At a large intermountain area university on the United States mainland, all 415 Polynesian American and 18,117 European American students who had completed an intake during the academic years spanning 1996 to 2013 were 
included in the sample. Intake records were found for 165 men $(39.8 \%)$ and 250 women $(60.2 \%)$. The participants' mean age was $22.2 ; 248(59.8 \%)$ reported that they were single, whereas $149(35.9 \%)$ reported that they were married, six (1.5\%) reported that they were divorced, and $12(2.8 \%)$ did not report their relationship status. These individuals were from a variety of Polynesian racial backgrounds (Native Hawaiian, Tongan, Samoan, Fijian, and Maori). Those who had reported that their ethnicity was Hawaiian and Pacific Islander (PI) were considered to be of Polynesian descent, except those who reported being PI but also reported a country of birth or country of citizenship that would traditionally be considered Asian (e.g., China, Hong Kong, India, Indonesia, Japan, Malaysia, Mongolia, Philippines, Singapore, South Korea, Sri Lanka, Taiwan, Thailand, Vietnam). Using this method, we narrowed the subject pool to those of Polynesian heritage, thereby avoiding the historically problematic issue of ethnic lumping regarding "Pacific Islanders" (Allen \& Heppner, 2011). For the sample of European American students, the mean age was 22.5 years $(S D=3.9), 58.9 \%$ were female, $55.6 \%$ were single, $42.9 \%$ were married, $1.4 \%$ were divorced, and $0.1 \%$ were widowed.

Generally speaking, counseling centers across the United States have adequate methods of collecting data from their student-clients. Although many counseling centers have well-intentioned methods of accurate and sound record keeping, some issues are bound to arise. These record keeping issues could be due to clerical and/or research assistant data entry errors, clients dropping out of treatment prematurely leading to incomplete measures, or transitioning from paper to electronic records. Although the counseling center where our data were gathered strived to maintain accurate and complete records, the aforementioned issues unfortunately occurred. Specifically, due to clerical and/or research assistant data entry errors and difficulties in transitioning from paper to electronic records during the years of 1996 to 2008, some students were missing one or more of the questionnaires, including pertinent items in each measure. We identified 346 (210 females and 136 males; $M$ age $=22.2$ years) Polynesian students for which we located a combination of the Family Concerns Survey (FCS), Presenting Problems Checklist (PPC), and Outcome Questionnaire (OQ). Of the Polynesian students included in this study, complete records of all questionnaires were available for 236 (156 females and 80 males, $M$ age $=22.6$ ) students. Due to the relatively small sample size of Polynesian American student-clients involved in this study and because there were no conceptually compelling reasons to exclude participants with missing data, we included all data available for each analysis. Thus, the analyses for each questionnaire show different sample size numbers of clients. For data analysis of the FCS, the sample sizes for student groups were 227 Polynesian American students and 18,117 
European American students, and for the analysis of the PPC, the sample sizes were 316 Polynesian American students and 18,117 European American students.

\section{Setting}

Over the past 17 years, the university counseling center from which data were collected for this study has used a range of 21 to 28 full-time, staff psychologists; three to five psychology interns; and 16 to 22 practicum doctoral students in any given year. Over this time span, there have been 320 counselors who have provided services at the counseling center. This number includes 32 staff psychologists, 259 students in training, and 28 individuals who saw clients at the center as students and who later also provided services at the center as a member of the staff. From this group of 320 counselors, $44 \%(n=$ 141) were female. Of this group of counselors, $77.8 \%(n=249)$ reported White, $1.6 \%(n=5)$ reported Polynesian, and $15.6 \%(n=50)$ a diverse racial/ ethnic background, including African American, American Indian, and Asian American. In addition, 5\% $(n=16)$ of the counselors reported that they were from a country outside the United States.

Counseling sessions involve a wide variety of theoretical orientations (e.g., cognitive-behavioral, acceptance and commitment therapy, interpersonal). Students who request counseling are assigned to the first available psychologist or doctoral student, and they receive treatment as usual according to that clinician's theoretical orientation. In addition, students can be referred to one of over 20 psychotherapy groups held each semester, as well as biofeedback services. Unless student-clients have specific requests regarding a therapist (e.g., a particular therapist, a particular theoretical orientation, male or female therapist, etc.), they are assigned according to availability of staff psychologists, interns, and doctoral students with careful attention to matching severity levels at intake to clinicians with appropriate levels of competence.

\section{Measures}

A variety of measures were included in this study: a demographic questionnaire, three measures administered at intake, and one that was administered prior to each counseling session. These are described in more detail next.

Demographic Questionnaire (DQ). This measure was used to gather general demographic information (e.g., gender, age, ethnicity, citizenship, religious preference), as well as previous counseling experience. 
FCS. The FCS is designed to assess the occurrence of traumatic family history events that may have influenced students' psychological development (Kearney et al., 2005). Students are asked to indicate whether or not each event happened in their family during childhood or adolescence. The list of 18 family experiences includes parental divorce or permanent separation, frequent moving, parental unemployment, frequent and hostile conflict, death of a parent, parents with drinking/drug or gambling problems, physical or sexual abuse, rape/sexual assault, family member diagnosed with or hospitalized for a mental disorder, attempted or completed suicide, family member with a debilitating illness, family member with an eating problem, and family member with criminal activity. It includes 18 items that are ranked on a 0 to 2 scale $(0=$ no, $1=$ unsure, $2=y e s)$. Items on this measure are presented in Table 1. The Cronbach's alpha for this study was .78.

The PPC. This 42-item self-report measure (Draper, Jennings, \& Barón, 2003) was designed to assess the degree to which students experience distress in several major areas of life functioning. Developed by the Counseling and Mental Health Center at the University of Texas at Austin (Draper et al., 2003), this checklist is used by many counseling centers across the country, including the counseling center from which our data were collected. The measure was constructed based on a review of 12 PPCs submitted by various counseling centers. Items were rationally selected with the goal of constructing a list of problems that was comprehensive and not redundant. The checklist was completed as part of the intake procedure at the counseling center. Clients responded to each item twice, once using the stem "Indicate the extent to which the problem is currently causing you distress," and another time using the stem "For how long have you had the problem." A Likert-type scale of 0 (none) to 4 (extreme) was used for the first stem, and a Likert-type scale of 1 (less than a week) to 6 (more than 3 years) was used for the second stem.

Items in the instrument measure a variety of topics including academic stress, college life adjustment, values, emotional distress, and body image (Draper et al., 2003). Additional items assess perfectionism, depression, sexual orientation concerns, and self-esteem, among others. Therefore, clinicians receive information for each item along two dimensions, one score indicating how much a student is distressed by that particular difficulty, and another score indicating how long they have experienced that problem. The total scale shows a Cronbach's alpha of .90 (Draper et al., 2003). The Cronbach's alpha for this study was .94 .

Based on the typical use of the data from the PPC and the FCS, we chose to use the item-level analytic strategy due to its clinical relevance. Clinicians at this counseling center viewed the data from these measures item by item. 


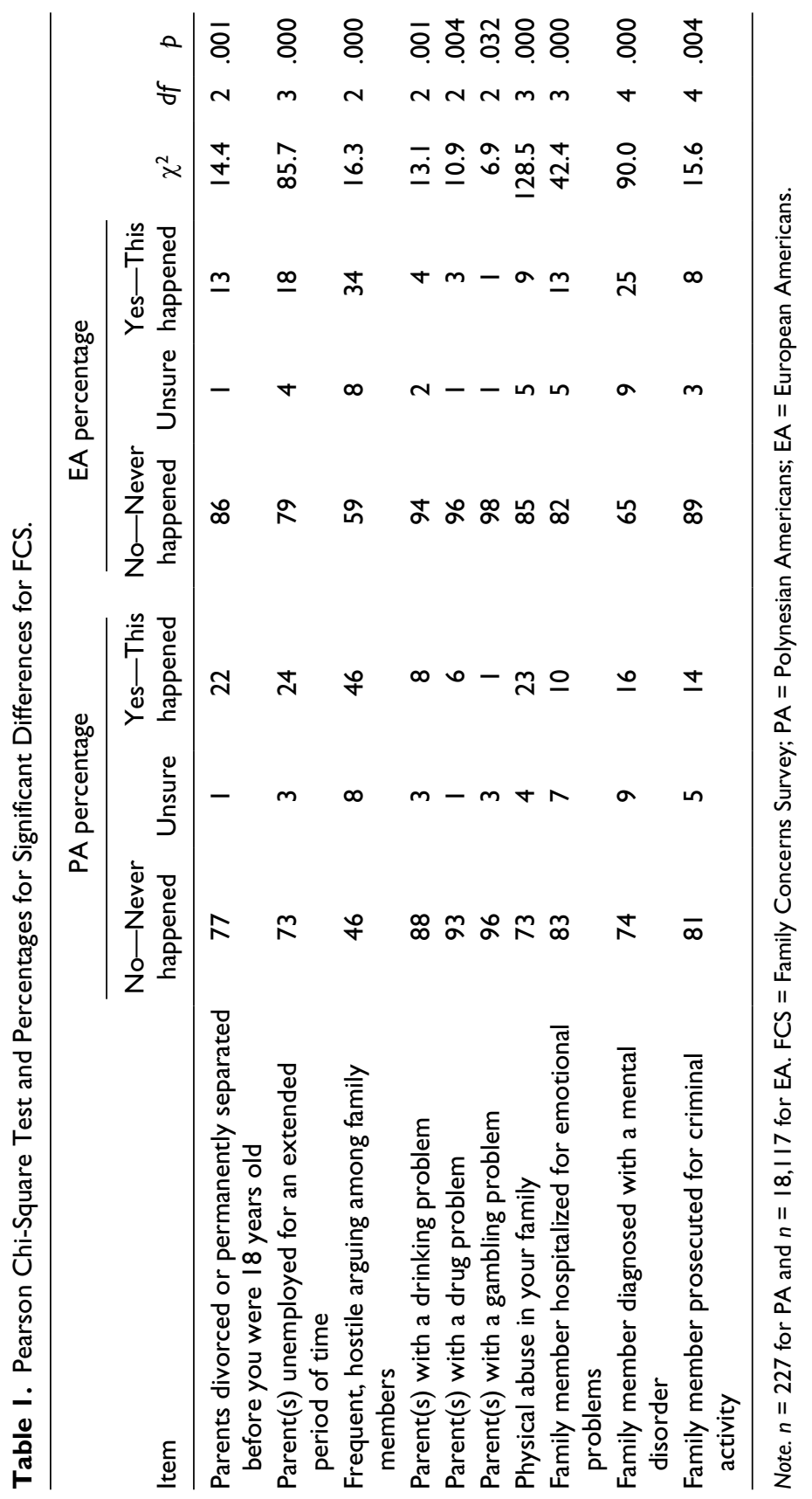


Each item is crucial and useful in helping psychotherapists at the targeted counseling center to make important decisions about the student-client and the approach to treatment.

The OQ-45. This commonly used measure of therapy outcome with college students has been shown to be sensitive to change (Lambert \& Finch, 1999). It is a 45 -item, self-report measure designed to provide a global assessment of client distress (Lambert, Lunnen, Umphress, Hansen, \& Burlingame, 1994). Items are rated on a 5-point scale from never to almost always. For example, Item 2 reads, "I tire quickly," to which students respond with a 0 (never), 1 (rarely), 2 (sometimes), 3 (frequently), or 4 (almost always). Higher scores indicate greater levels of distress. Typically, a score of 63 or lower falls in the subclinical range, whereas scores greater than 63 represent a clinical population (Kadera, Lambert, \& Andrews, 1996). The standard deviation for this measure is 15 points, and 14-point increases or decreases indicate reliable change. Prior research indicates that the OQ-45 has excellent internal reliability alpha at .93 , test-retest reliability at .84 , and concurrent validity with other instruments ( $r=.58$ to .84 ; Kadera et al., 1996). The Cronbach's alpha for the data in this study was .92 .

\section{Results}

\section{Utilization of Services}

We examined differences in rates of service utilization at the counseling center based on the number and proportion of students by race. During the years 1996 to 2013, roughly 32,500 students, on average, attended the university each year. On average, $292(0.009 \%)$ Hawaiian and/or PI students were enrolled per year at the university from 1996 to 2013. Across that same time period, approximately 7,000 students identified themselves as Hawaiian and/ or PI. During the 17-year period, 31,855 students completed intake questionnaires at the counseling center, with $1.3 \%$ of those students identifying as Hawaiian and/or PI, and 72.6\% identifying as White/European American. Exact annual student enrollment data and the number of those students seeking services at the counseling center each year from 1996 to 2013 were used to calculate odds ratios for the differences in counseling center utilization between Polynesian and European Americans. To avoid bias in the overall estimate, we aggregated the odds ratios calculated based on the data for each year. Specifically, we averaged the natural log of the odds ratios, weighted by standard error, and subsequently converted the value back to the metric of odds ratio for ease of interpretation (an odds ratio of 1.50 would be considered 
small, and an odds ratio of 1.0 indicates no difference). The resulting aggregate odds ratio of 1.02 indicated essentially no difference in utilization rates across race: Polynesian and European American students were almost equally likely to complete an intake at the counseling center, relative to their proportions on campus.

In a subsequent analysis, we examined the number of counseling sessions completed by Polynesian Americans. We found that a significantly higher proportion of Polynesian American students did not return after intake (13.6\%, $n=36$, crosstabulation, $z$ test $=2.12, p<.05)$, compared with European American students $(9.3 \%, n=1,794)$. To examine trends over time using survival statistics to evaluate differences across race, we conducted two Cox regression models of the data for (a) total number of sessions completed and (b) total duration of treatment in days, controlling for OQ-45 intake score and client gender and age. Both of these models reached statistical significance for number of sessions, $\chi^{2}(d f=3)=257.72, p<.0001$ and for treatment duration, $\chi^{2}(d f=3)=153.91, p<.0001$; Polynesian Americans attended fewer overall sessions and remained in treatment for a shorter duration than European Americans.

FCS. We sought to examine differences between Polynesian and European Americans relative to family concerns at intake. Given the 3 anchor points on the FCS (i.e., No-Never Happened, Unsure, Yes-This Happened), we conducted chi-square analyses for nominal data between "No" and "Yes" responses to examine significant differences between Polynesian and European Americans. We found significant differences between Polynesian Americans and European Americans on 10 of the 18 items, with Polynesian Americans reporting higher rates of family concerns on eight of those 10 items (see Table 1). The following were of greater concern to Polynesian American students than to European American counterparts: parents divorced or permanently separated before the student reached the age of 18, parents unemployed for an extended period of time, frequent and hostile arguing among family members, parent(s) with a drinking problem, parent(s) with a drug problem, parent(s) with a gambling problem, physical abuse in the family, and family member prosecuted for criminal activity. European Americans showed statistically higher rates on two of the 10 significantly different items: family member hospitalized for emotional problems and family member diagnosed with a mental disorder.

PPC. Regarding the PPC, which uses a 5-point Likert-type scale, we performed Kruskal-Wallis tests for ordinal data to examine differences between Polynesian and European American students related to their presenting 
problems and distress. Regarding distress level, of the 42 questions on the PPC indicating the distress that brought the students to the counseling center, Polynesian and European American students differed significantly on 11, which are presented in Table 2. The following are areas in which Polynesian American students exhibited higher distress rates: academic or schoolwork or grades; adjustment to the university; alcohol and drugs; concentration; ethnic/racial discrimination; homesickness; irritability, anger, or hostility; reading or study skills problems; test, speech, or performance anxiety; and time management. European Americans statistically showed higher rates of distress on one of the 11 items: making friends.

Students also reported information regarding the duration of presenting problems on the PPC. Polynesian and European American students statistically differed on nine of the 42 items, which are also shown in Table 2. Polynesian Americans reported longer duration for the following eight items: adjustment to the university; alcohol and drugs; ethnic/racial discrimination; homesickness; rape, sexual assault, or unwanted sex; reading or study skills problems; relationship with family, parents, or siblings; and test, speech, or performance anxiety. European Americans reported longer duration on making friends. Although the options on this checklist are oriented toward the university experience rather than the family, Polynesian American students demonstrated significantly greater distress and duration of presenting problems on almost as many family items as academic items.

\section{Psychotherapy Outcome}

We performed repeated measures analysis of covariance (ANCOVA) to examine changes in OQ-45 scores controlling for initial symptom severity. We found no differences between Polynesian and European American students based on last OQ scores $(F=.69, p=.41)$. In addition, we conducted a mixed design (split plot) analysis of variance (ANOVA) to assess differential change in $\mathrm{OQ}$ scores (including subscales) over time according to ethnic group membership. We found no significant interaction between time and group membership, $F(1,17,233)=0.53, p=.96$. We also found no significant main effect for group, $F(1,17,233)=3.69, p=.054$, but did find a significant main effect for time, $F(1,17,233)=240.88, p<.001$.

\section{Discussion}

Multicultural psychology lacks empirical investigations and research of Polynesian Americans related to counseling process and outcome, specifically among the student populations (Allen \& Heppner, 2011). This study of 


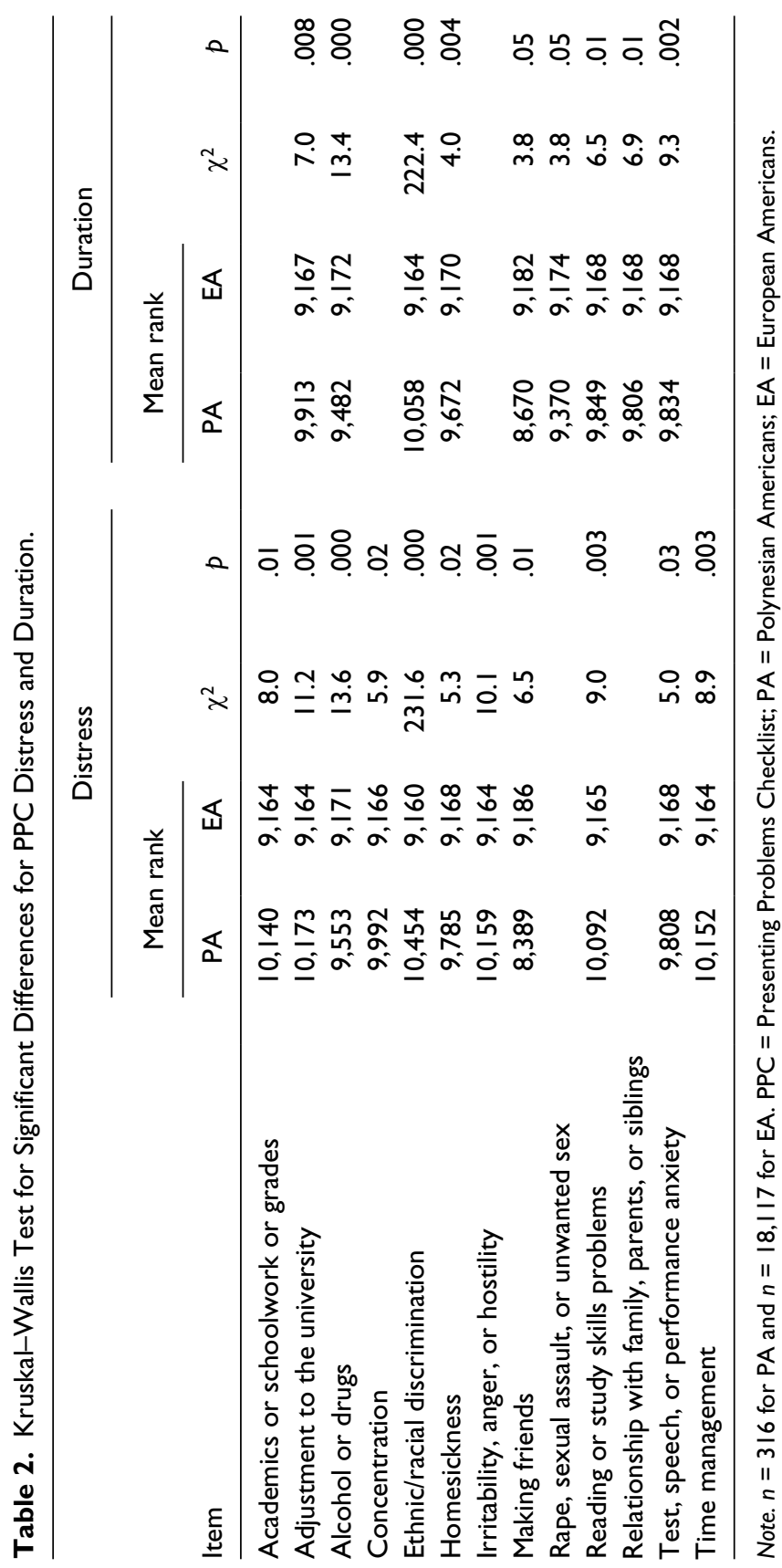


Polynesian American college students presents new and important findings about college counseling utilization, as well as presenting personal and family concerns, among Polynesian American college students.

\section{Utilization of Professional Mental Health Counseling and Psychotherapy Outcomes}

Contrary to our initial hypothesis, we found no statistical differences between Polynesian and European American students' initial counseling utilization rates, which is consistent with the findings by Hayes et al. (2011). We assumed that Polynesian American students would be more hesitant to seek help at college counseling centers than European Americans. However, although they initially utilized the counseling center at the same rate, Polynesian students were less likely to return after intake $(13.6 \%$ of Polynesian American nonreturns vs. 9.3\% of European American nonreturns). It is possible that this cultural group is less likely to remain in counseling and to continually use professional counseling services as a first-line defense when they experience psychological difficulties. We hypothesize that their cultural values may make them more likely to turn to their family for guidance and support (Allen \& Heppner, 2011; Allen \& Smith, 2015; Braun $\&$ Browne, 1998) as this approach may be a better fit within the Polynesian cultural context. It is possible that seeking and obtaining counseling from a qualified professional could be interpreted as personal weakness and bring disgrace and disrespect to Polynesian students' families; thus, they would be less likely to return to therapy repeatedly.

For these students, a point of emotional exhaustion (their threshhold limit) may need to be reached in order for them to overcome any cultural hesitation and present for treatment. This may explain why the intensity of their problems, when they finally do present at college counseling centers, appears to be significantly elevated in comparison to the intensity reported by students who are more likely to utilize psychotherapeutic services at an earlier period of distress. Similarly, having a cultural stigma against counseling may explain why so many of these students change their minds and terminate therapy after the initial intake (Gary, 2005).

Even among students who returned for a second session, Polynesian American students attended fewer overall sessions and remained in treatment for shorter duration than European Americans when we controlled for OQ-45 intake score, client gender, and client age. Again, we hypothesize that cultural and familial factors that differ between the cultures differentially affect students' participation in therapy (Braun \& Browne, 1998). It is also possible that Polynesian American students may not feel comfortable meeting with 
counselors who are almost all European American, which could be another possible explanation of early dropout and fewer attended sessions. Perhaps a part of the difference in their utilization rates may be attributed to them not feeling culturally and racially connected and close to their counselors (Allen \& Heppner, 2011).

Despite the higher symptomatic distress levels at intake, no difference was found in outcome factors. Our results indicate that both groups improved, and they did not differ significantly on therapy participation when we controlled for initial OQ-45 scores, gender, and age. These results matched Lambert et al.'s (2006) study that found no differences in treatment outcomes among racial/ethnic groups. Apparently, although Polynesian American students were seemingly more likely to attend fewer sessions or stop coming to therapy earlier in treatment than their European American peers, both groups improved according to their self-reported OQ-45 scores.

Future research could focus on assessing the contributing factors for Polynesian American students' lower therapy utilization rates. This information would be important for developing programming that helps this population increase engagement in therapy at college counseling centers.

\section{Differences in Distress and Duration of Presenting Problems Between Polynesian and European Americans}

On both of the instruments measuring stress factors and concerns, all but three of the items with statistically significant differences showed more intense concern and distress among the Polynesian American students. For convenience in discussion, we grouped items with significant differences as family concerns, academic struggles, and emotional challenges.

Family concerns. In this sample of students seeking mental health services at a university counseling center, Polynesian American students reported more family concerns related to divorce and unemployment than European Americans. A possible explanation could be that concerns over issues of family instability may have resulted in increased distress for Polynesian American students due to the emphasis of family unity and harmony in their culture (Allen \& Heppner, 2011; Allen \& Smith, 2015). Polynesian American students also indicated more concern with factors such as parents' difficulties with alcohol, drugs, gambling, and criminal activity. Participants' worry about the stability of relationships among family members could be partly due to their collectivistic nature in the family, as well as an increased attention for the welfare of their families (Allen \& Heppner, 2011; Allen \& Smith, 
2015). Regardless of whether one or both of these possible factors may be involved, these worries and challenges can add to the overall distress and distractibility of students, limiting their ability to succeed in college.

Generally, Polynesian families tend to seek emotional help within the family structure, perhaps through counsel from the sage patriarchs or matriarchs of the family (Allen \& Heppner, 2011; Allen \& Smith, 2015). Polynesian Americans may not report being either diagnosed with a mental disorder or hospitalized due to this internal family coping style (Allen \& Heppner, 2011; Allen \& Smith, 2015). In contrast, European Americans endorsed higher rates in these areas, possibly due to their use of different coping strategies. Another possible explanation could be that mental illness is more stigmatized or "taboo" among Polynesian American families compared with European American families, leading to a lack of psychoeducation, knowledge about mental health, and possible underreporting of psychological disorders.

The only items on the intake surveys on which European American students showed significantly more anxiety/distress than their Polynesian American counterparts were being able to make friends and having a family member with a mental disorder. These findings might be attributable to the same cultural expectation of family support and closeness (Braun \& Browne, 1998). Because Polynesian American individuals may turn to family (Allen \& Heppner, 2011; Allen \& Smith, 2015) rather than friends or professional mental health treatment, they have less expectation of not having friends and more experience in dealing with problems nonprofessionally. Also as fewer family members seek professional help, fewer would receive a diagnosis from a mental health professional (Braun \& Browne, 1998).

Academic struggles. Polynesian American students in this sample, seeking help at college counseling centers, reported struggling academically. They may worry about their academic work and grades, and may struggle with decisions about their major and career. On the questionnaires, students mentioned difficulties in specific academic areas: reading and study skills as well as anxiety over the tests, speeches, or performances. These anxieties may be exacerbated by their family worries and stress, as well as by their reported struggles including concentrating and managing their time. These difficulties in academic disciplines perhaps indicate that these students may not be sufficiently prepared for the higher levels of rigorous study habits needed to excel in some college courses. Further assessment could examine potential language barriers, test/performance anxiety, and overall adjustment to college life. The link between academic struggles, family, and cultural values might also be explored. 
Emotional challenges. Polynesian American college students reported significantly higher rates of difficulty adjusting to college life than European American students. They indicated significantly higher rates of irritability, anger, and hostility. The total weight of family, academic, and emotional problems could be associated with sleeping problems and in more extreme cases with alcohol or drugs. Another significant concern that needs additional attention reported on duration of the problem among Polynesian American college students involves rape, sexual assault, and unwanted sexual activities.

Particularly damaging among the emotional challenges faced by Polynesian American college students is ethnic/racial discrimination. Supposedly casual but offensive racial comments or slights, known as racial microaggressions (Sue et al., 2007), although they may seem on the surface to be without malice, can lead to students of color, including those of Polynesian descent, feeling downgraded, unimportant, and even inadequate or incompetent for college, particularly if the campus is predominantly European American. Studies have examined negative effects of racial discrimination among Polynesians in New Zealand (Harris et al., 2006), a topic that warrants additional attention, particularly across college campuses in the United States with Polynesian Americans.

The increased distress levels among Polynesian American students related to their overall performance at school and their potential to use drugs or alcohol to self-medicate are alarming. Ethnic and racial discrimination and the possibility of rape, sexual assault, and/or unwanted sexual activities might be particularly influential on self-concept, self-esteem, and self-efficacy. College counseling centers should reach out with appropriate treatment to Polynesian American students before the distress and duration of their concerns increase and negatively affect their academic experiences.

Need for adapting outreach and services. The presenting concerns of Polynesian American students need specific attention; thus, it is vital that college counseling centers reach out to Polynesian American students across the United States. The one item on distress and duration of a presenting problem that European Americans endorsed more frequently than Polynesian Americans was related to making friends. Due to Polynesian American students' seemingly close relationships with family members and their devotion to maintaining family harmony (Allen \& Heppner, 2011; Allen \& Smith, 2015), they possibly could become more stressed about family members (rather than friends) if there are problems and interpersonal tensions within the family (Braun \& Browne, 1998).

The number and variety of presenting concerns and the significantly higher levels of distress and duration among this sample of Polynesian 
American students indicate a need for additional services at counseling centers across the nation, particularly at colleges where there may be a large population of Polynesian American students. College counseling centers could attend to these students by improving their outreach and treatment practices. Initial steps might include the following:

- Learning more about the Polynesian Americans' cultural context and being culturally sensitive to these students (Allen \& Heppner, 2011).

- Gaining knowledge of their specific cultural coping strategies (Allen \& Heppner, 2011; Allen \& Smith, 2015) and applying them in session.

- Understanding Polynesian Americans' strong cultural identity (Allen et al., 2013).

We are concerned that Polynesian American students attended fewer psychotherapy sessions at a mainland U.S. college counseling center over the span of 17 years than their European American peers. This tendency to not remain in psychotherapy may be associated with other helpful cultural remedies and strategies that Polynesian Americans utilize to alleviate emotional struggles outside of the counseling sessions. Counselors could consider learning and striving to understand Polynesian culture and values, and being sensitive to their worldview and cultural context when meeting with Polynesian American students. We emphasize that bridges need to be built between counseling centers and Polynesian American students, outreach efforts need to be more inclusive of this student group, and counseling centers across U.S. campuses need to be aware of this increasing population and their psychological struggles.

\section{Study Limitations}

A limitation to this study is the age range of Polynesian American students. Because the mean age of participants in this study was in the early 20 s, researchers cannot infer generalizability across Polynesian American students of all ages. Factors in this age group such as life stage, developmental level, and context-appropriate family standards could have influenced the results found. In addition, it is possible that the demographics associated with Polynesian American students would be different from those of other Polynesian Americans. Demographic factors such as socioeconomic status and educational attainment may differ in this sample from the wider Polynesian American population. 
Another limitation to this study is the incompleteness of measures from clients across samples due to clerical errors and the transition from paper to electronic records. However, we did not find another study of this kind. Furthermore, we deemed that the benefit of including as many students' data as possible was more important than analyzing a smaller subset of subjects based on time or complete data. Thus, we believe that the impact of some of the few missing measures across samples was less important than the potential benefits gained.

\section{Implications for Practice}

The results of this study highlight the need for therapists working with Polynesian American students, particularly at college counseling centers, to explicitly attend to the students' presenting concerns and to learn how these concerns can be both understood and ameliorated through the students' cultural context. While attending sessions, Polynesian American students reported problems with unwanted sexual experiences, problems with their family, and distress about a myriad of other concerns. Therapists should be aware of and appropriately assess for these potential difficulties in their work with Polynesian American students.

Furthermore, therapists who are appropriately sensitive to cultural contexts when they engage in psychotherapy with Polynesian American students, who attend to collectivistic worldviews, and who act in close coordination with the students' families and religious communities, may increase the likelihood that students will participate in campus counseling services and possibly decrease their likelihood of dropping out of higher education (Cervantes \& Parham, 2005; Yeh, Arora, \& Wu, 2006). In addition, counseling center therapists can explicitly attend to cultural considerations such as building on students' preferred methods for handling distress and maintaining psychological well-being (Bernal, Jiménez-Chafey, \& Domenech Rodríguez, 2009).

\section{Conclusion and Suggestions for Future Research}

This study of Polynesian American college students' presenting concerns and distress levels at intake was conducted not merely to expand our understanding of this understudied and underserved population but also to facilitate improved outreach procedures and appropriate cultural adaptations to mental health services (Benish, Quintana, \& Wampold, 2011; Smith \& Khawaja, 2011). Currently, the field of psychology, particularly counseling psychology, understands very little about the experiences of Polynesian American college students. According to the results of this study, Polynesian American students 
are significantly more distressed with family concerns, academic struggles, and emotional challenges, than their European American peers. Although mental health practices are being effectively adapted to better meet the needs of many other ethnic minority groups at counseling centers across the United States, it is past time for the benefits of multicultural and crosscultural research to be extended to this population. By increasing their awareness of the levels of distress and types of presenting concerns specific to Polynesian American students, counselors can increase the effectiveness of their work with this underserved population.

Although a few studies have investigated the well-being, identity, trauma, and resilience of Native Hawaiians in recent years (McCubbin, 2006; McCubbin \& Dang, 2010; McCubbin et al., 2008), additional research on other Polynesian American student groups (Tongan, Samoan, Fijian, Maori) in the United States is strongly encouraged (Allen \& Heppner, 2011; Allen et al., 2013; Allen \& Smith, 2015), particularly focusing on family stressors, family coping, and cultural factors relating to help-seeking and perceptions of mental health. Future research in these areas can add to our knowledge of the cultural contexts, family and personal concerns, academic struggles, racial issues, and psychological well-being of these cultural groups while they are pursuing higher education on U.S. college campuses.

\section{Declaration of Conflicting Interests}

The authors declared no potential conflicts of interest with respect to the research, authorship, and/or publication of this article.

\section{Funding}

The authors received no financial support for the research, authorship, and/or publication of this article.

\section{References}

Allen, G. E., Garriott, P. O., Reyes, C. J., \& Hsieh, C. (2013). Racial identity, phenotype, and self-esteem among biracial Polynesian/White individuals. Family Relations, 62, 82-91.

Allen, G. E., \& Heppner, P. P. (2011). Religiosity, coping, and psychological wellbeing among Latter-Day Saint Polynesians in the U.S. Asian American Journal of Psychology, 2, 13-24.

Allen, G. E., \& Smith, T. B. (2015). Collectivistic coping strategies for distress among Polynesian Americans. Psychological Services, 12, 322-329.

Archer, J., Jr., \& Cooper, S. (1998). The Jossey-Bass Higher and Adult Education Series. Counseling and mental health services on campus: A handbook of contemporary practices and challenges. San Francisco, CA: Jossey-Bass. 
Benish, S. G., Quintana, S., \& Wampold, B. E. (2011). Culturally adapted psychotherapy and the legitimacy of myth: A direct-comparison meta-analysis. Journal of Counseling Psychology, 58, 279-289.

Bernal, G., Jiménez-Chafey, M. I., \& Domenech Rodríguez, M. M. (2009). Cultural adaptation of treatments: A resource for considering culture in evidence-based practice. Professional Psychology: Research and Practice, 40, 361-368.

Braun, K. L., \& Browne, C. V. (1998). Perceptions of dementia, caregiving, and help seeking among Asian and Pacific Islander Americans. Health \& Social Work, 23, 262-274.

Carlton, B. S., Goebert, D. A., Miyamoto, R. H., Andrade, N. N., Hishinuma, E. S., Makini, G. K. J., . . Nishimura, S. T. (2006). Resilience, family adversity and well-being among Hawaiian and non-Hawaiian adolescents. International Journal of Social Psychiatry, 52, 291-308. doi:10.1177/0020764006065136

Cervantes, J. M., \& Parham, T. A. (2005). Toward a meaningful spirituality for people of color: Lessons for the counseling practitioner. Cultural Diversity \& Ethnic Minority Psychology, 11, 69-81.

Draper, M. R., Jennings, J., \& Barón, A. (2003). Factor analysis and concurrent validity of a University Counseling Center Presenting Problems Checklist. Retrieved from cmhc.utexas.edu/pdf/FactorAnalysis.pdf

Gary, F. A. (2005). Stigma: Barrier to mental health care among ethnic minorities. Issues in Mental Health Nursing, 26, 979-999.

Griner, D., \& Smith, T. B. (2006). Culturally adapted mental health intervention: A meta-analytic review. Psychotherapy: Theory, Research, Practice, Training, 43, 531.

Harris, R., Tobias, M., Jeffreys, M., Waldegrave, K., Karlsen, S., \& Nazroo, J. (2006). Racism and health: The relationship between experience of racial discrimination and health in New Zealand. Social Science \& Medicine, 63, 1428-1441.

Hayes, J. A., Youn, S. J., Castonguay, L. G., Locke, B. D., McAleavey, A. A., \& Nordberg, S. (2011). Rates and predictors of counseling center use among college students of color. Journal of College Counseling, 14, 105-116.

Ibaraki, A. Y., \& Hall, G. C. N. (2014). The components of cultural match in psychotherapy. Journal of Social \& Clinical Psychology, 33, 936-953. Retrieved from http://doi.org/10.1521/jscp.2014.33.10.936

Kadera, S. W., Lambert, M. J., \& Andrews, A. A. (1996). How much therapy is really enough: A session-by-session analysis of the psychotherapy dose-effect relationship. Journal of Psychotherapy Research and Practice, 5, 132-151.

Kearney, L. K., Draper, M., \& Barón, A. (2005). Counseling utilization by ethnic minority college students. Cultural Diversity \& Ethnic Minority Psychology, 11, 272-285.

Kitzrow, M. A. (2003). The mental health needs of today's college students: Challenges and recommendations. Journal of Student Affairs Research and Practice, 41, 167-181.

Lambert, M. J., \& Finch, A. E. (1999). The Outcome Questionnaire. In M. E. Maruish (Ed.), The use of psychological testing for treatment planning and outcome assessment (2nd ed., pp. 831-870). Mahwah, NJ: Lawrence Erlbaum. 
Lambert, M. J., Lunnen, K., Umphress, V., Hansen, N., \& Burlingame, G. M. (1994). Administration and scoring manual for the Outcome Questionnaire (OQ-45.1). Salt Lake City, UT: IHC Center for Behavioral Healthcare Efficacy.

Lambert, M. J., Smart, D. W., Campbell, M. P., Hawkins, E. J., Harmon, C., \& Slade, K. L. (2006). Psychotherapy outcome, as measured by the OQ-45, in African American, Asian/Pacific Islander, Latino/a, and Native American clients compared with matched Caucasian clients. Journal of College Student Psychotherapy, 20(4), 17-29.

McCubbin, L. D. (2006). The role of indigenous family ethnic schema on well-being among Native Hawaiian families. Contemporary Nursing Journal: Community \& Family Health, 23, 170-180.

McCubbin, L. D., \& Dang, T. (2010). Native Hawaiian identity and measurement: An ecological perspective on indigenous identity development. In J. G. Ponterotto, J. M. Casas, L. A. Suzuki, \& C. M. Alexander (Eds.), Handbook of multicultural counseling (3rd ed.). Thousand Oaks, CA: SAGE.

McCubbin, L. D., Ishikawa, M., \& McCubbin, H. I. (2008). Kanaka Maoli: Native Hawaiians and their testimony of trauma and resilience. In A. Marsella, J. Johnson, P. Watson, \& J. Gryczynski (Eds.), Ethnocultural perspectives on disaster and trauma: Foundations, issues and applications (pp. 271-298). New York, NY: Springer.

Smith, R., \& Khawaja, N. (2011). A review of the acculturation experiences of international students. International Journal of Intercultural Relations, 35, 699-713.

Sue, D. W., Capodilupo, C. M., Torino, G. C., Bucceri, J. M., Holder, A., Nadal, K. L., \& Esquilin, M. (2007). Racial microaggressions in everyday life: Implications for clinical practice. American Psychologist, 62, 271-286.

U.S. Bureau of the Census. (2010). People: Fact finder. Retrieved from http://www. census.gov/2010census/

Yeh, C. J., Kwong Arora, A. K., \& Wu, K. (2006). A new theoretical model of collectivistic coping. In P. T. P. Wong, \& C. J. Wong (Eds.), Handbook of multicultural perspectives on stress and coping (pp. 55-72). New York: Springer.

\section{Author Biographies}

G. E. Kawika Allen received his $\mathrm{PhD}$ in counseling psychology from the University of Missouri-Columbia and completed his predoctoral internship at Duke University. His research areas include religiosity/spirituality, psychotherapy process and outcome, and psychological well-being and adjustment among racial ethnic minorities, specifically Polynesians. He is currently an assistant professor in the counseling psychology doctoral program at Brigham Young University (BYU).

Jon Cox graduated with a PhD in clinical psychology in 2008. He completed his clinical internship at the University of Utah Neuropsychiatric Institute. Since 2012, he has worked as an assistant clinical professor at the BYU Counseling and Psychological Services. 
Timothy B. Smith is a professor and department chair of counseling psychology at BYU. He is a Fellow of APA Division 17 and a Fulbright Scholar. He recently authored the APA book Foundations of Multicultural Psychology.

Ofa Hafoka received a bachelor's of arts degree in psychology from BYU-Hawaii. She is currently a $\mathrm{PhD}$ candidate in counseling psychology at BYU.

Derek Griner is a licensed psychologist and assistant clinical faculty member at BYU. He currently holds a joint appointment in BYU's counseling psychology doctoral program and Counseling and Psychological Services. He is committed to furthering knowledge surrounding diversity. In 2007, he received APA's Jeffrey S. Tanaka PhD Memorial Dissertation Award in Psychology, as well as Division 17's Section on Ethnic and Racial Diversity Outstanding Contribution to Scholarship on Race \& Ethnicity Award.

Mark Beecher received his $\mathrm{PhD}$ in counseling psychology from BYU. He is currently a clinical professor at BYU with a joint appointment in the Counseling and Psychological Services office and the counseling psychology doctoral program. His research interests include group psychotherapy, multicultural counseling, psychotherapy, and assessment/services for students with disabilities. 